University of Wollongong

Research Online

Australian Institute for Innovative Materials -

Papers

Australian Institute for Innovative Materials

$1-1-2013$

Biofunctionalized anti-corrosive silane coatings for magnesium alloys

Xiao Liu

University of Wollongong, xiaol@uow.edu.au

Zhilian Yue

University of Wollongong, zyue@uow.edu.au

Tony Romeo

University of Wollongong, tromeo@uow.edu.au

Jan Weber

Boston Scientific Maastricht, Netherlands

Torsten Scheuermann

Boston Scientific Technology Center

See next page for additional authors

Follow this and additional works at: https://ro.uow.edu.au/aiimpapers

Part of the Engineering Commons, and the Physical Sciences and Mathematics Commons

Research Online is the open access institutional repository for the University of Wollongong. For further information contact the UOW Library: research-pubs@uow.edu.au 


\title{
Biofunctionalized anti-corrosive silane coatings for magnesium alloys
}

\begin{abstract}
Biodegradable magnesium alloys are advantageous in various implant applications, as they reduce the risks associated with permanent metallic implants. However, a rapid corrosion rate is usually a hindrance in biomedical applications. Here we report a facile two step procedure to introduce multifunctional, anticorrosive coatings on $\mathrm{Mg}$ alloys, such as AZ31. The first step involves treating the $\mathrm{NaOH}$-activated $\mathrm{Mg}$ with bistriethoxysilylethane to immobilize a layer of densely crosslinked silane coating with good corrosion resistance; the second step is to impart amine functionality to the surface by treating the modified Mg with 3-amino-propyltrimethoxysilane. We characterized the two-layer anticorrosive coating of Mg alloy AZ31 by Fourier transform infrared spectroscopy, static contact angle measurement and optical profilometry, potentiodynamic polarization and AC impedance measurements. Furthermore, heparin was covalently conjugated onto the silane-treated AZ31 to render the coating haemocompatible, as demonstrated by reduced platelet adhesion on the heparinized surface. The method reported here is also applicable to the preparation of other types of biofunctional, anti-corrosive coatings and thus of significant interest in biodegradable implant applications.
\end{abstract}

\section{Keywords}

coatings, magnesium, alloys, corrosive, biofunctionalized, silane, anti

Disciplines

Engineering | Physical Sciences and Mathematics

\section{Publication Details}

Liu, X., Yue, Z., Romeo, T., Weber, J., Scheuermann, T., Moulton, S. \& Wallace, G. (2013). Biofunctionalized anti-corrosive silane coatings for magnesium alloys. Acta Biomaterialia, 9 (10), 8671-8677.

\section{Authors}

Xiao Liu, Zhilian Yue, Tony Romeo, Jan Weber, Torsten Scheuermann, Simon E. Moulton, and Gordon G. Wallace 


\section{Bio-functionalised anticorrosive silane coatings for magnesium alloys}

Xiao Liu ${ }^{1}$, Zhilian Yue ${ }^{1}$, Tony Romeo ${ }^{1}$, Jan Weber ${ }^{2}$, Torsten Scheuermann ${ }^{3}$, Simon E. Moulton ${ }^{1}$ and G. G. Wallace ${ }^{1}$

1. ARC Centre of Excellence for Electromaterials Science, Intelligent Polymer Research Institute, University of Wollongong, Wollongong, NSW 2522, Australia.

2. Boston Scientific Maastricht, Gaetano Martinolaan 50,6229 GS Maastricht,Netherlands 3. Boston Scientific Technology Center, Perchtinger Strasse 6, 81379 Munich Germany

* Corresponding author:

Tel: +61-2-4298 1443

Fax: +61-2-4221 3114

E-mail address: smoulton@uow.edu.au 


\section{Abstract}

Biodegradable magnesium (Mg) alloys are advantageous in various implant applications, as they reduce the risks associated with permanent metallic implants. However, the fast corrosion rate is usually a hindrance in biomedical applications. Here we report a facile twostep procedure to introduce multifunctional, anticorrosive coatings on $\mathrm{Mg}$ alloys, such as AZ31. The first step involves treating the $\mathrm{NaOH}$-activated $\mathrm{Mg}$ with bistriethoxysilylethane (BTSE) to immobilise a layer of densely crosslinked silane coating with good corrosion resistance; the second step is to impart amine functionality to the surface by treating the modified Mg with 3-amino-propyltrimethoxysilane ( $\gamma$-APS). We characterised the two-layer anticorrosive coating of AZ31 Mg alloy by Fourier transform infrared spectroscopy, static contact angle measurement and optical profilometry, potentiodynamic polarization and AC impedance measurements. Furthermore, heparin was covalently conjugated onto the silane treated AZ31 to render the coating haemocompatible, as demonstrated by reduced platelet adhesion on the heparinised surface. The method reported here is also applicable to the preparation of other types of biofunctional, anticorrosive coatings, and thus of significant interest in biodegradable implant applications.

Keywords: Magnesium alloy; heparin; silane; corrosion; biodegradable metallic implants; platelet adhesion 


\section{Introduction}

Metallic implants, such as stents, bone plates and artificial joints, are widely used in the human body. However, there are serious problems associated with permanent metallic implants, including restenosis, thrombosis, physical irritation, potential inflammatory responses and inability to adapt to the growth and changes of the human body [1]. In some cases, additional surgery is required to remove the implant after the tissue has sufficiently healed [2] and, as a consequence, researchers and clinicians are looking towards biodegradable implants that, once implanted, only remain for an appropriate period to "fix" the problem and then disappear [3]. Coupled with their strong mechanical properties and low cytotoxicity, magnesium $(\mathrm{Mg})$ alloys have attracted increasing attention as candidate materials for biodegradable stents and bone plates $[1,4-6]$. However, the potential clinical applications of $\mathrm{Mg}$ alloys have been hindered by their poor corrosion resistance. Fast corrosion of $\mathrm{Mg}$ alloys results in the generation of hydrogen bubbles and $\mathrm{pH}$ changes, which will damage surrounding tissues [7]. More seriously, fast corrosion can lead to early loss of mechanical stability of the Mg alloy implant before the end of the healing process [4]. Therefore, an appropriate corrosion rate becomes an essential requirement for the clinical applications of Mg alloys in biodegradable metallic implants.

To improve the corrosion resistance of $\mathrm{Mg}$ alloys, several techniques have been employed, including development of new $\mathrm{Mg}$ alloys $[8,9]$, surface modification via nitrogen ion implantation [10, 11], anodizing [12], and the use of conversion coatings [13-15]. Among these technologies, silane based anticorrosive coatings of $\mathrm{Mg}$ alloys have been proven to be effective, economical and environmentally benign $[16,17]$. Silanes are a group of siliconbased organic-inorganic materials with the general formula $\mathrm{R}^{\prime}\left(\mathrm{CH}_{2}\right)_{n} \mathrm{Si}(\mathrm{OR})_{3}$, where $\mathrm{R}^{\prime}$ is an 
organofunctional group and $\mathrm{R}$ is a hydrolysable alkoxy group. When in contact with water, silanes hydrolyse to yield silanol groups $(\mathrm{SiOH})$ that permit attachment to hydrated metal surfaces (Metal-OH) via the formation of Si-O-metal bonds [18]. In the meantime, the silanol groups undergo self-crosslinking via siloxane bonds (Si-O-Si), resulting in an organic protective layer chemically bound to the metallic substrates $[19,20]$.

Bistriethoxysilylethane (BTSE) and 3-amino-propyltrimethoxysilane ( $\gamma$-APS) are widely studied bis-silane and mono-silanes, respectively. Such silanes can provide functional moieties that enable further attachment of bioactive molecules to enhance the interfacial properties of metal implants with surrounding cells and tissue [21]. However, it is reported that the amino group of $\gamma$-APS preferentially bonds to metal surfaces, which results in defects in the silane coatings, thus allowing water to penetrate to the silane-metal interface $[22,23]$. Compared to functional mono-silanes, non-functional "bis-silanes" provide better corrosion protection due to the formation of densely crosslinked 3D polysiloxane networks and stronger interfacial adhesion at various metal surfaces, including steel, Al alloy, Cu alloy, and Mg alloy [24]. To take advantage of both types of silanes, a two-step BTSE- $\gamma$-APS coating treatment has been developed by Van Ooij's group to provide good corrosion protection for aluminium and steel [25]. However, to our knowledge, this two-step silane coating has not been applied to $\mathrm{Mg}$ alloys.

Another key requirement for biodegradable metallic implants, especially for cardiovascular stents, is blood compatibility. Adhesion of platelets can induce thrombus formation and, consequently, implant failure [26]. Heparin remains the most frequently used anticoagulant reagent. Surface modification with heparin has been intensively explored for increasing the thromboresistance of biomedical implants. Previous studies demonstrated that heparin 
coated stents reduced stent thrombosis $[27,28]$, and resulted in favourable event-free survival after 6 months [27].

In this study, we developed a two-step BTSE- $\gamma$-APS coating strategy to produce a biofunctionalised anticorrosive coating on AZ31 Mg alloy. The silane layer was analysed using FTIR and optical profilometry; the anticorrosion properties of the coating was assessed by potentiodynamic polarization and $\mathrm{AC}$ impedance measurements. We also demonstrated that bioactive heparin can be covalently attached to the silane modified Mg alloy surface. Using this technology, we demonstrated both markedly improved corrosion resistance and blood compatibility of the resulting Mg alloy.

\section{Materials and Methods:}

\section{Materials}

All reagents were used as received. Bistriethoxysilylethane (BTSE), 3-Aminopropyltrimethoxysilane $\quad(\gamma$-APS), $\quad \mathrm{N}$-hydroxysuccinimide $\quad$ (NHS), 1-ethyl-3-(3dimethylaminopropyl) carbodiimide (EDC), 2-morpholinoethanesulfonic acid (MES), heparin, phosphate buffered saline (PBS), toluidine blue $\mathrm{O}$ (TBO) and glutaraldehyde were from Sigma-Aldrich, Australia. AZ31 Mg alloy sheet with the nominal mass composition of $96 \%$ $\mathrm{Mg}, 3 \% \mathrm{Al}$ and $1 \% \mathrm{Zn}$ was purchased from Goodfellow Metals, UK. Simulated body fluid (SBF) solution was freshly prepared which contained $5.403 \mathrm{~g} \mathrm{NaCl}, 0.504 \mathrm{~g} \mathrm{NaHCO}_{3}, 0.426 \mathrm{~g}$ $\mathrm{Na}_{2} \mathrm{CO}_{3}, 0.225 \mathrm{~g} \mathrm{KCl}, 0.230 \mathrm{~g} \mathrm{~K}_{2} \mathrm{HPO}_{4} \cdot 3 \mathrm{H}_{2} \mathrm{O}, 0.311 \mathrm{~g} \mathrm{MgCl}_{2} \cdot 6 \mathrm{H}_{2} \mathrm{O}, 0.8 \mathrm{~g} \mathrm{NaOH}, 17.892 \mathrm{~g}$ HEPES, $0.293 \mathrm{~g} \mathrm{CaCl}_{2}$ and $0.072 \mathrm{~g} \mathrm{Na}_{2} \mathrm{SO}_{4}$ in $1000 \mathrm{ml}$ Milli-Q water.

Silanization of AZ31 Mg alloy 
The $2.0 \mathrm{~mm}$ thick AZ31 Mg alloy sheets were cut into $15 \mathrm{~mm} \times 20 \mathrm{~mm}$ pieces and polished with progressively fine SiC papers up to grit 2000. The samples were ultrasonically cleaned using acetone, dried in air, and then immersed in a $3.0 \mathrm{M} \mathrm{NaOH}$ solution for $2 \mathrm{~h}$ to produce a uniform hydroxide layer on the substrates. The $\mathrm{NaOH}$-activated $\mathrm{Mg}$ substrates are referred to as $\mathrm{Mg}-\mathrm{OH}$.

BTSE or $\gamma$-APS solution was prepared by mixing $5 \%$ silane, $90 \%$ ethanol and $5 \%$ MilliQ water. The solutions were stirred at room temperature (RT) for $1 \mathrm{~h}$ to allow the hydrolysis to proceed. AZ31 samples were then immersed in the hydrolysed BTSE solution at RT for $1 \mathrm{~h}$, dried with hot air, and then cured at $120^{\circ} \mathrm{C}$ for $1 \mathrm{~h}$. For the second step coating, the BTSE treated samples, denoted as Mg-B, were soaked in the $\gamma$-APS solution at RT for 30 min before being cured at $120^{\circ} \mathrm{C}$ for $1 \mathrm{~h}$. The resultant samples were denoted as Mg-B-A.

Surface modification of $M g-B-A$ with heparin

$\mathrm{EDC} \bullet \mathrm{HCl}$ and $\mathrm{NHS}$ were added to a heparin solution $(5.0 \mathrm{mg} / \mathrm{ml})$ in $\mathrm{MES}$ buffer to a final concentration of $2.0 \mathrm{mg} / \mathrm{ml}$. Mg-B-A samples were immersed in the above solution and shaken at RT for $4 \mathrm{~h}$. The heparinised samples (Mg-B-A-Heparin) were rinsed 5 times in both PBS and then water, respectively.

\section{Physiochemical characterisation of the modified AZ31 samples}

The surface modified ZA31 samples were investigated using a SHIMADZU IRPrestige-21 Fourier transform infrared spectrophotometer. Attenuated total reflection Fourier transform infrared (ATR-FTIR) spectra were recorded at a resolution of $4.0 \mathrm{~cm}^{-1}$ and a scan range of $2000 \mathrm{~cm}^{-1}$ to $700 \mathrm{~cm}^{-1}$. The surface morphology was analysed using a Veeco optical profiler NT9000 (Veeco Instruments Inc. USA). Static water contact angles were measured 
using the sessile drop method (2.0 $\mu \mathrm{L}$, Milli $Q$ water) with a Dataphysics OCA20 Goniometer (DataPhysics Instruments GmbH, Germany).

The amounts of surface accessible heparin were quantified using a TBO assay $[29,30]$. In general, AZ31 samples were immersed in a freshly prepared TBO solution $(0.04$ wt\% in 0.01 $\mathrm{M} \mathrm{HCl} / 0.2 \mathrm{wt} \% \mathrm{NaCl}$ solution, $2.0 \mathrm{ml}$ per sample) and shaken gently at $\mathrm{RT}$ for $4 \mathrm{~h}$ followed by rinsing five times with MilliQ water. Then the AZ31 samples were soaked in ethanol/NaOH (4/1 v/v) solution for $10 \mathrm{~min}$, and the released TBO was quantified by measuring the optical density of the solution at $530 \mathrm{~nm}$. A standard curve was established using a series of standard solutions of heparin.

\section{Anticorrosion properties of modified AZ31 sample}

Potentiodynamic polarization curves were recorded at a scan rate of $5.0 \mathrm{mV} / \mathrm{s}$ in SBF using a CHI 660 system (CH Instruments, Inc. USA). Electrochemical impedance spectroscopy (EIS) measurements were carried out in SBF solution using a three electrode cell comprising of a $1.0 \mathrm{~cm}^{2}$ modified AZ31 as the working electrode, a platinum mesh auxiliary electrode and $\mathrm{Ag} \mid \mathrm{AgCl}(3.0 \mathrm{M} \mathrm{NaCl})$ reference electrode. The samples were placed in electrolyte and the open circle potential monitored for $1 \mathrm{~h}$. Impedance spectroscopy was conducted between $0.05 \mathrm{~Hz}$ and $100 \mathrm{kHz}$ at the measured open-circuit potential with an AC amplitude of $10 \mathrm{mV}$ using a Gamry Potentiostatic PCl 750 system (Gamry Instruments, USA). The long term immersion experiments were performed at $37^{\circ} \mathrm{C}$, the samples were then removed and the electrochemical measurement performed at room temperature $\left(24^{\circ} \mathrm{C}\right)$.

Platelet adhesion analysis 
Fresh whole rat blood, with EDTA as anticoagulant was obtained from Australia Animal Resources Centre. The blood samples were centrifuged at $300 \times \mathrm{xg}$ for 10 minutes at RT to isolate platelet rich plasma (PRP). After removal of the PRP, the remaining samples were centrifuged at $2500 \times \mathrm{xg}$ for $10 \mathrm{~min}$ at RT to isolate platelet pool plasma (PPP). The number of platelets in the PRP was diluted to $1 \times 10^{8}$ cells/ml by mixing PRP with PPP. Modified AZ31 samples were immersed into PRP for $1 \mathrm{~h}$ at $37^{\circ} \mathrm{C}$. Thereafter, the samples were rinsed twice with PBS, fixed with $2 \%$ glutaraldehyde for $2 \mathrm{~h}$, dehydrated in a series of increasing concentrations of ethanol to 100 per cent, and then observed using a JEOL 7500FA FESEM.

\section{Statistical analysis}

All data are expressed as mean $\pm S D$, unless specified; an unpaired student's t-test was used for comparison, and a p-value of less than 0.05 was considered to be statistically significant.

\section{Results and discussion:}

\section{Surface modification of AZ31 Mg alloy}

The surface modification scheme for AZ31 Mg alloy is shown in Figure 1. To facilitate silane coating, AZ31 Mg alloy was pre-treated with $\mathrm{NaOH}$ to generate surface hydroxide groups (Mg-OH); BTSE and $\gamma$-APS were hydrolysed to yield silanol groups. $\mathrm{Mg}-\mathrm{OH}$ was then sequentially treated with the hydrolysed BTSE and $\gamma$-APS to introduce a two-layer silane coating through oxane bond formation with elimination of water. These processes are accompanied by in situ polycondensation of the hydrolysed BSTE and $\gamma$-APS to form the polysiloxane networks with surface amine functionality. In this study, heparin was employed as an example of bioactive molecules, and conjugated onto the aminized silane coating of AZ31 Mg alloy to improve the substrate's blood compatibility. 
FTIR spectrum (Figure 2) clearly show peaks around $1045-1127 \mathrm{~cm}^{-1}$ that correspond to the Si-O asymmetric stretching in -Si-O-Si- $[19,25]$. Subsequent coating with $\gamma$-APS significantly increases the intensities of these peaks, with the appearance of a new peak around 1570 $\mathrm{cm}^{-1}$ that is assigned to the protonated amino groups [25]. Our FTIR results are consistent with those reported for BTSE and/or $\gamma$-APS treated Al, Fe and Mg samples [17, 19, 25, 31].

\section{Physiochemical properties of the surface modified AZ31 Mg alloys}

The influence of modification on the surface morphology of the Mg alloys was investigated (Figure 3). Bare AZ31 sample showed a uniformly patterned morphology associated with the polishing procedure, with surface roughness ( $\mathrm{Ra}$ ) of $148.7 \pm 16.5 \mathrm{~nm}$ (Table 1 ). $\mathrm{Mg}-\mathrm{OH}$ still retained the polishing-induced regular pattern, but with increased Ra of $203.1 \pm 6.5 \mathrm{~nm}$. A much rougher surface morphology $(\mathrm{Ra} \approx 910.3 \pm 2.2$ ) was noted for $\mathrm{Mg}-\mathrm{B}$, attributable to the BTSE coating. The subsequent modification with $\gamma$-APS markedly reduced the Ra of Mg-B-A to $761.7 \pm 51.2 \mathrm{~nm}$, and this is presumably due to the existence of the grafted $\gamma$-APS as an overlayer on the modified AZ31 surface. Further conjugation of heparin onto Mg-B-A resulted in the roughest surface morphology amongst the tested samples, with a Ra of $2320 \pm 57.7 \mathrm{~nm}$. During the two-step silane coating and heparin modification, the polishinginduced regular pattern that is evident on bare AZ31 becomes less distinctive.

The influence of modification is also reflected in the changes in surface wettability of the modified AZ31 alloys, as characterised by static contact angle measurement (Figure 4). Bare AZ31 exhibits surface hydrophobicity, with a contact angle of $75.2 \pm 2.0^{\circ}$. The pre-treatment with $\mathrm{NaOH}$ increased the surface hydrophilicity of $\mathrm{Mg}-\mathrm{OH}$, giving a water contact angle of $14.4 \pm 1.9^{\circ}$. As expected, incorporation of the BTSE layer re-established the surface 
hydrophobicity, with the static contact angle increasing to $103.2 \pm 1.8^{\circ}$. Compared to $\mathrm{Mg}-\mathrm{B}$, $\mathrm{Mg}-\mathrm{B}-\mathrm{A}$ is less hydrophobic with a lower contact angle of $78.2 \pm 1.5^{\circ}$, ascribed to the presence of surface amine moieties. Further modification with heparin rendered the surface hydrophilic [32], as characterised by a much lower water contact angle of $21.4 \pm 2.2^{\circ}$.

\section{Corrosion resistance properties of the modified AZ31 Mg alloys}

Functional silanes, such as $\gamma$-APS, have often been used for modification of stainless steel [33] and $\mathrm{Ti}[30,34]$ to provide surface functionality for post chemical anchorage of biomolecules (e.g. collagen, heparin and fibronectin), with a view to improving the biocompatibility of these metallic implants. However, functional silanes, such as $\gamma$-APS, have failed to provide effective corrosion resistance for metals and their alloys [24]. As reported by others $[24,25]$, there are two regions within a silane coating which can provide corrosion resistance: the crosslinked outer silane layer enriched with Si-O-Si bonds and the interfacial layer dominated by Si-O-metal bonds. The more hydrophobic the outer layer, the lower the water penetration rate [25]. As a bis-silane such as BTSE is more hydrophobic than $\gamma$-APS, and the interfacial regions between bis-silane and metal contains a higher density of Si-Ometal bonds than that of a mono-silane, BTSE provides better corrosion protection than $\gamma$ APS at both the outer layer and the interfacial layer. Silanes have been widely used as coupling agents in clinical applications for more than 50 years, particularly in dentistry as adhesion promoters [35]. They have proven to be safe in vivo $[35,36]$. However, the applications of silane coatings in dentistry are limited by bond degradation [35] associated with the hydrolytic cleaving of the siloxane bonds. In this works for degradable implant applications, the purpose of the silane coatings is to slow down the initial corrosion rate rather than totally stop the corrosion process. Therefore bond degradation is expected 
when water penetrates to the interface between the silane coating and the Mg substrate resulting in detachment of the silane coating. Previous studies have shown that stents will be encapsulated by neointimal tissue after implantation [37], therefore as long as detachment occurs after the neointimal formation, silane coating fragments may be retained and localised rather than being lost into the bloodstream. So the risk associate with silane coating detachment can be controlled by the development of novel silane coupling agents with increased bond strength and hydrolytic stability. The two-step coating procedure reported here aims to combine the advantages of both BTSE and $\gamma$-APS to produce anticorrosive coatings with surface functionality. The chemically bound BTSE layer introduced in the 1st step coating serves as a hydrophobic barrier, improving the hydrolytic stability of the silane coating and preventing the underlying Mg from rapid corrosion. This is clearly demonstrated in the corrosion resistance study (Figure 5 and Figure 6) of the modified Mg alloys.

Polarization curves of the modified AZ31 Mg alloys are shown in Figure 5 and the corrosion current $\left(I_{\text {corr }}\right)$ values are summarised in Table 1 . Compared to bare $\mathrm{Mg}$, the $\mathrm{I}_{\text {corr }}$ value decreased by $\sim 68 \%$ for $\mathrm{Mg}-\mathrm{B}$, and $\sim 89 \%$ for $\mathrm{Mg}-\mathrm{B}-\mathrm{A}$. As $\mathrm{I}_{\text {corr }}$ is directly proportional to the corrosion rate [38], a distinct improvement in corrosion resistance is indicated. The corrosion of magnesium involves reaction of $\mathrm{H}_{2} \mathrm{O}$ with $\mathrm{Mg}$ to produce $\mathrm{Mg}(\mathrm{OH})_{2}$ and $\mathrm{H}_{2}$. The overall reaction includes an anodic $\left(\mathrm{Mg} \rightarrow \mathrm{Mg}^{2+}+2 \mathrm{e}^{-}\right)$and cathodic reaction $\left(2 \mathrm{H}_{2} \mathrm{O}+2 \mathrm{e}^{-}\right.$ $\rightarrow \mathrm{H}_{2}+2 \mathrm{OH}^{-}$) [39]. After $\mathrm{NaOH}$ passivation, AZ31 surfaces were covered by a layer of $\mathrm{Mg}(\mathrm{OH})_{2}$ film. The metal cation transport dominates the anodic kinetics as the anodic Mg dissolution reaction occurs on the $A Z 31$ surface underlying the $\mathrm{Mg}(\mathrm{OH})_{2}$ film. The $\mathrm{Mg}(\mathrm{OH})_{2}$ film cannot stop electrolyte penetration as it is porous and unstable in the aqueous environment. The 
charge transfer associated with the cathodic reaction can occur, both beneath and on top of the film, which results in a higher cathodic current density compared to silane coated samples. After BTSE coating, the exchange current density from the cathodic reaction is reduced because the hydrophobic silane film acts as a physical barrier to retard water penetration and electron transport. The anodic dissolution reactions rates were also slowed as the silane coating blocks mass transport of $\mathrm{Mg}^{2+}[24]$. At the same time, the formation of Si-O-Mg bonds at the interface also blocks some anodic reactions [24, 31]. The second layer of $\gamma$-APS coating reduces the electrolyte penetration and electron transport process which further reduces the corrosion current by around one order of magnitude as compared to uncoated AZ31 samples. The shift of corrosion potential towards the cathodic direction also indicates that the hydrophobic silane film acts as a physical barrier to retard the electrolyte penetration [31]. Further modification of $\mathrm{Mg}-\mathrm{B}-\mathrm{A}$ with heparin resulted in an increase in $\mathrm{I}_{\text {corr }}$ from $0.9 \mu \mathrm{A}$ to $1.87 \mu \mathrm{A}$, which may be due to the outer layer silane film being saturated with the electrolyte during the covalent conjugation process and thus partly losing its function as a physical barrier to retard the electrolyte penetration [24]. However, even in this case, the $\mathrm{I}_{\text {corr }}$ of Mg-B-A-Heparin is still lower than that of bare AZ31.

The anticorrosive properties of modified AZ31 samples were also assessed by electrochemical impedance spectroscopy (EIS) (Figure 6). In the whole frequency range examined, applying the BTSE coating and BTSE- $\gamma$-APS coating resulted in a progressive increase in impedance. Compared to bare AZ31, the impedance of Mg-B-A increased by one order of magnitude as a result of the non-conductive silane coating, which indicates effective protection of the metal surface [24]. Similar to the $I_{\text {corr }}$ result, the impedance of Mg-B-A-heparin sample is reduced to a similar level as that of $\mathrm{Mg}-\mathrm{B}$, but is still 4 times 
higher than that of the untreated AZ31 sample. EIS spectra of Mg and Mg-A-B-heparin samples were also recorded in SBF at $37^{\circ} \mathrm{C}$ every $6 \mathrm{~h}$ over a $42 \mathrm{~h}$ period (Figure 7). Two capacitive semicircles are clearly observed over the first hour for the uncoated AZ31 and silane coated samples. For uncoated AZ31 samples, the middle frequency ( $\mathrm{mf}$ ) semicircles disappeared and a low frequency $(I f)$ inductive loop appears after $6 \mathrm{~h}$ immersion indicating severe pitting corrosion [40]. For silane coated samples (Mg-B-A-heparin), both semicircles are clearly evident up to $24 \mathrm{~h}$ immersion, after which time both semicircles appear to merge into one large semicircle with an associated increase in impedance suggesting improved corrosion protection $[17,41]$.

\section{Platelet adhesion behaviour on the modified AZ31 Mg alloys}

Compared to the single functional silane coating approach reported previously $[16,17,42]$, this work utilizes BTSE as the first layer of coating to provide a hydrophobic barrier while minimising the interference from the functional groups (e.g. amino group [23]), which is important for the improved corrosion resistance of modified AZ31. In addition, the unique two-step coating offers potential for further modification to improve the biocompatibility of Mg alloy implants. In this work, heparin has been covalently conjugated onto the modified Mg surface via the amino groups provided by the grafted $\gamma$-APS. The density of surface accessible heparin, as determined by the TBO assay, is $\sim 12 \mu \mathrm{g} / \mathrm{cm}^{2}$ (Figure 8 ), which is significantly higher than that of the blank control. This value is comparable to those of heparin modified surfaces that were shown to effectively improve blood compatibility [30, 43]. To assess whether the heparin retained bioactivity after covalent conjugation, platelet adhesion assays were performed across different samples. In contrast to the silane modified 
AZ31 samples, significantly lower platelet adhesion was observed on the Mg-B-A-heparin surface (Figure 9).

\section{Conclusions}

Through the route of a two-step coating process, we have developed biofunctionalised, anticorrosive silane coatings for biodegradable Mg alloys. Compared to bare AZ31 Mg alloy, Mg-B-A-Heparin exhibits both an improved corrosion resistance and reduced platelet adhesion. The development of a surface modification strategy that can simultaneously control the Mg alloy corrosion resistance and inhibit platelet adhesion will inevitably have major significance for improving the blood compatibility of biodegradable metallic implants. In addition, this work opens up new avenues and a potential platform to functionalise $\mathrm{Mg}$ alloys based on chemical anchorage and in situ condensation of two types of silanes, a process which then provides functional groups for the further immobilization of essential biological components to facilitate the ongoing development of biodegradable metallic implants.

\section{Acknowledgements}

The authors would like to acknowledge Boston Scientific and ACES for funding through ARC linkage grant LP0990621. This research used equipment funded by Australian Research Council and located at the UOW Electron Microscopy Centre and Australian National Fabrication Facility (ANFF) - Materials Node. Special thanks to Mr Darren Attard from UOW Electron Microscopy Centre and Dr. Stephen Beirne from Intelligent Polymer Research Institute for assistance in sample preparation. 


\section{References:}

[1] Heublein B, Rohde R, Kaese V, Niemeyer M, Hartung W, Haverich A. Biocorrosion of magnesium alloys: a new principle in cardiovascular implant technology? Heart. 2003;89:651-6.

[2] Peterson HA. Metallic Implant Removal in Children. Journal of Pediatric Orthopaedics. 2005;25:107-15.

[3] Hermawan H, Dubé D, Mantovani D. Developments in metallic biodegradable stents. Acta Biomaterialia. 2010;6:1693-7.

[4] Staiger MP, Pietak AM, Huadmai J, Dias G. Magnesium and its alloys as orthopedic biomaterials: A review. Biomaterials. 2006;27:1728-34.

[5] Witte F, Hort N, Vogt C, Cohen S, Kainer KU, Willumeit R, et al. Degradable biomaterials based on magnesium corrosion. Current Opinion in Solid State and Materials Science. 2008;12:63-72.

[6] Witte $F$, Ulrich $H$, Rudert $M$, Willbold E. Biodegradable magnesium scaffolds: Part 1: Appropriate inflammatory response. Journal of Biomedical Materials Research Part A. 2007;81A:748-56.

[7] Witte F. The history of biodegradable magnesium implants: A review. Acta Biomaterialia. 2010;6:1680-92.

[8] Song G. Control of biodegradation of biocompatable magnesium alloys. Corrosion Science. 2007;49:1696-701.

[9] Gu X, Zheng Y, Cheng Y, Zhong S, Xi T. In vitro corrosion and biocompatibility of binary magnesium alloys. Biomaterials. 2009;30:484-98.

[10] Tian XB, Wei CB, Yang SQ, Fu RKY, Chu PK. Corrosion resistance improvement of magnesium alloy using nitrogen plasma ion implantation. Surface and Coatings Technology. 2005;198:454-8.

[11] Nakatsugawa I, Martin R, Knystautas EJ. Improving corrosion resistance of AZ91D magnesium alloy by nitrogen ion implantation. Corrosion. 1996;52:921-26.

[12] Blawert C, Dietzel W, Ghali E, Song G. Anodizing Treatments for Magnesium Alloys and Their Effect on Corrosion Resistance in Various Environments. Advanced Engineering Materials. 2006;8:511-33.

[13] Rudd AL, Breslin CB, Mansfeld F. The corrosion protection afforded by rare earth conversion coatings applied to magnesium. Corrosion Science. 2000;42:275-88.

[14] Grundmeier G, Schmidt W, Stratmann M. Corrosion protection by organic coatings: electrochemical mechanism and novel methods of investigation. Electrochimica Acta. 2000;45:2515-33.

[15] Gray JE, Luan B. Protective coatings on magnesium and its alloys - a critical review. Journal of Alloys and Compounds. 2002;336:88-113.

[16] Zucchi F, Grassi V, Frignani A, Monticelli C, Trabanelli G. Influence of a silane treatment on the corrosion resistance of a WE43 magnesium alloy. Surface and Coatings Technology. 2006;200:4136-43.

[17] Zucchi F, Frignani A, Grassi V, Balbo A, Trabanelli G. Organo-silane coatings for AZ31 magnesium alloy corrosion protection. Materials Chemistry and Physics. 2008;110:263-8.

[18] Plueddemann EP. Silane coupling agents: Springer; 1991.

[19] Van Ooij WJ, Subramanian V, Zhang C. Method of preventing corrosion of metals using silanes. US Patent 5,750,197; 1998. 
[20] van Ooij WJ, Zhu DQ, Prasad G, Jayaseelan S, Fu Y, Teredesai N. Silane based chromate replacements for corrosion control, paint adhesion, and rubber bonding. Surface Engineering. 2000;16:386-96.

[21] Weetall HH. Preparation of immobilized proteins covalently coupled through silane coupling agents to inorganic supports. Applied Biochemistry and Biotechnology. 1993;41:157-88.

[22] Quinton JS, Dastoor PC. Conformational dynamics of $\gamma$-APS on the iron oxide surface: an adsorption kinetic study using XPS and ToF-SIMS. Surface and Interface Analysis. 2000;30:21-4.

[23] Subramanian V, van Ooij WJ. Effect of the amine functional group on corrosion rate of iron coated with films of organofunctional silanes. Corrosion. 1998;54:204-.

[24] Zhu D, van Ooij WJ. Corrosion protection of AA 2024-T3 by bis-[3(triethoxysilyl)propyl]tetrasulfide in sodium chloride solution.: Part 2: mechanism for corrosion protection. Corrosion Science. 2003;45:2177-97.

[25] Song J, Van Ooij WJ. Bonding and corrosion protection mechanisms of gamma-APS and BTSE silane films on aluminum substrates. Journal of Adhesion Science and Technology. 2003;17:2191-221.

[26] Meadows TA, Bhatt DL. Clinical Aspects of Platelet Inhibitors and Thrombus Formation. Circulation Research. 2007;100:1261-75.

[27] Serruys PW, Emanuelsson H, van der Giessen W, Lunn AC, Kiemeney F, Macaya C, et al. Heparin-Coated Palmaz-Schatz Stents in Human Coronary Arteries : Early Outcome of the Benestent-II Pilot Study. Circulation. 1996;93:412-22.

[28] Hårdhammar PA, van Beusekom HMM, Emanuelsson HU, Hofma SH, Albertsson PA, Verdouw PD, et al. Reduction in Thrombotic Events With Heparin-Coated Palmaz-Schatz Stents in Normal Porcine Coronary Arteries. Circulation. 1996;93:423-30.

[29] Yue Z, Liu X, Molino PJ, Wallace GG. Bio-functionalisation of polydimethylsiloxane with hyaluronic acid and hyaluronic acid - Collagen conjugate for neural interfacing. Biomaterials. 2011;32:4714-24.

[30] Li G, Yang P, Qin W, Maitz MF, Zhou S, Huang N. The effect of coimmobilizing heparin and fibronectin on titanium on hemocompatibility and endothelialization. Biomaterials. 2011;32:4691-703.

[31] Zhu D, van Ooij WJ. Corrosion protection of metals by water-based silane mixtures of bis-[trimethoxysilylpropyl]amine and vinyltriacetoxysilane. Progress in Organic Coatings. 2004;49:42-53.

[32] Thorslund S, Sanchez J, Larsson R, Nikolajeff F, Bergquist J. Bioactive heparin immobilized onto microfluidic channels in poly(dimethylsiloxane) results in hydrophilic surface properties. Colloids and Surfaces B: Biointerfaces. 2005;46:240-7.

[33] Müller R, Abke J, Schnell E, Macionczyk F, Gbureck U, Mehrl R, et al. Surface engineering of stainless steel materials by covalent collagen immobilization to improve implant biocompatibility. Biomaterials. 2005;26:6962-72.

[34] Middleton CA, Pendegrass CJ, Gordon D, Jacob J, Blunn GW. Fibronectin silanized titanium alloy: $A$ bioinductive and durable coating to enhance fibroblast attachment in vitro. Journal of Biomedical Materials Research Part A. 2007;83A:1032-8.

[35] Lung CYK, Matinlinna JP. Aspects of silane coupling agents and surface conditioning in dentistry: An overview. Dental Materials. 2012;28:467-77. 
[36] Matinlinna JP, Lassila L, Ozcan M, Yli-Urpo A, Vallittu PK. An introduction to silanes and their clinical applications in dentistry. The International journal of prosthodontics. 2004;17:155.

[37] Komatsu R, Ueda M, Naruko T, Kojima A, Becker AE. Neointimal tissue response at sites of coronary stenting in humans: macroscopic, histological, and immunohistochemical analyses. Circulation. 1998;98:224-33.

[38] Jones DA. Principles and prevention of corrosion 1996.

[39] Song G, Atrens A. Understanding Magnesium Corrosion-A Framework for Improved Alloy Performance. Advanced Engineering Materials. 2003;5:837-58.

[40] Alvarez-Lopez M, Pereda MD, del Valle JA, Fernandez-Lorenzo M, Garcia-Alonso MC, Ruano OA, et al. Corrosion behaviour of AZ31 magnesium alloy with different grain sizes in simulated biological fluids. Acta Biomaterialia. 2010;6:1763-71.

[41] Montemor MF, Ferreira MGS. Electrochemical study of modified bis[triethoxysilylpropyl] tetrasulfide silane films applied on the AZ31 Mg alloy. Electrochimica Acta. 2007;52:7486-95.

[42] Kim J, Wong KC, Wong PC, Kulinich SA, Metson JB, Mitchell KAR. Characterization of AZ91 magnesium alloy and organosilane adsorption on its surface. Applied Surface Science. 2007;253:4197-207.

[43] Yang Z, Wang J, Luo R, Maitz MF, Jing F, Sun H, et al. The covalent immobilization of heparin to pulsed-plasma polymeric allylamine films on $316 \mathrm{~L}$ stainless steel and the resulting effects on hemocompatibility. Biomaterials. 2010;31:2072-83. 
Figure 1. A: Hydrolysis process of BTSE; B: Hydrolysis process of $\gamma$-APS, and C: Schematic illustration of the surface modification procedure of AZ31Mg alloy.

Figure 2. FTIR spectra of $\mathrm{Mg}, \mathrm{Mg}-\mathrm{OH}, \mathrm{Mg}-\mathrm{B}$ and $\mathrm{Mg}-\mathrm{B}-\mathrm{A}$.

Figure 3. Surface morphologies of $A Z 31$ samples with different treatment: fresh polished $\mathrm{Mg}$ (A), Mg-OH (B), Mg-B (C), Mg-B-A (D) and Mg-B-A-heparin (E).

Figure 4. Static water contact angles of $\mathrm{Mg}, \mathrm{Mg}-\mathrm{OH}, \mathrm{Mg}-\mathrm{B}, \mathrm{Mg}-\mathrm{B}-\mathrm{A}$ and $\mathrm{Mg}-\mathrm{B}-\mathrm{A}-\mathrm{Heparin}$ samples.

Figure 5. Polarization curves of $\mathrm{Mg}, \mathrm{Mg}-\mathrm{OH}, \mathrm{Mg}-\mathrm{B}, \mathrm{Mg}-\mathrm{B}-\mathrm{A}$ and $\mathrm{Mg}-\mathrm{B}-\mathrm{A}-\mathrm{Hep}$ arin samples.

Figure 6. Impedance spectra of $\mathrm{Mg}, \mathrm{Mg}-\mathrm{OH}, \mathrm{Mg}-\mathrm{B}, \mathrm{Mg}-\mathrm{B}-\mathrm{A}$ and $\mathrm{Mg}-\mathrm{B}-\mathrm{A}-\mathrm{hep}$ arin samples.

Figure 7.Impedance spectra of $\mathrm{Mg}$ and $\mathrm{Mg}-\mathrm{B}-\mathrm{A}$-heparin samples in SBF solution at $1,6,12$, $18,24,30,36$ and $42 \mathrm{~h}$.

Figure 8. Quantitative characterisation of the surface accessible heparins on Mg-B-A and Mg-B-A-Heparin samples.

Figure 9. Representative SEM micrographs of platelets on Mg-B-A (A) and Mg-B-A-heparin (B). The scale bars represent $2 \mu \mathrm{m}$.

Table 1: Contact angle, surface roughness (Ra), corrosion current ( $\mathrm{I}_{\text {corr }}$ ) and corrosion resistance $(\mathrm{Rp})$ values of $\mathrm{Mg}$ alloy samples after different treatments. The sample size $(\mathrm{n})$ for roughness and contact angle measurements is 5 and 3 for $I_{\text {corr }}$ and $R_{p}$.

\begin{tabular}{|c|c|c|c|c|c|}
\hline AZ31 Samples & Abbr*. & $\mathrm{Ra}(\mathrm{nm})$ & $\begin{array}{c}\text { Contact angle } \\
\left({ }^{\circ}\right)\end{array}$ & $\begin{array}{c}I_{\text {corr }} \\
\left(\mu \mathrm{A} / \mathrm{cm}^{2}\right) \\
\end{array}$ & $\mathrm{R}_{\mathrm{p}}\left(\mathrm{ohms} / \mathrm{cm}^{2}\right.$ ) \\
\hline As polished & $\mathrm{Mg}$ & $148.7 \pm 16.5$ & $75.2 \pm 2.0$ & $8.32 \pm 0.63$ & $2650 \pm 538$ \\
\hline $\mathrm{NaOH}$ passivated & $\mathrm{Mg}-\mathrm{OH}$ & $203.1 \pm 6.5$ & $14.4 \pm 1.9$ & $5.10 \pm 1.42$ & $3178 \pm 787$ \\
\hline BTSE coated & Mg-B & $910.3 \pm 2.2$ & $103.2 \pm 1.8$ & $2.69 \pm 0.31$ & $7788 \pm 2572$ \\
\hline BTSE+APS coated & Mg-B-A & $761.7 \pm 51.2$ & $78.2 \pm 1.5$ & $0.90 \pm 0.24$ & $13635 \pm 2745$ \\
\hline $\begin{array}{l}\text { BTSE+APS+heparin } \\
\text { coated }\end{array}$ & $\begin{array}{l}\text { Mg-B-A- } \\
\text { heparin }\end{array}$ & $2320 \pm 57.7$ & $21.4 \pm 2.2$ & $1.87 \pm 0.23$ & $9515 \pm 497$ \\
\hline
\end{tabular}

*Abbr = abbreviation

Table 1: Contact angle, surface roughness (Ra), corrosion current ( $\left.\mathrm{I}_{\text {corr }}\right)$ and corrosion resistance $(\mathrm{Rp})$ values of $\mathrm{Mg}$ alloy samples after different treatments. The sample size $(\mathrm{n})$ for roughness and contact angle measurements is 5 and 3 for $I_{\text {corr }}$ and $R_{p}$. 
IPRI/12100/07.01.13 